\title{
The role of social media data in operations and production management
}

\author{
Hing Kai Chan ${ }^{1}$, Ewelina Lacka², Rachel W. Y. Yee ${ }^{3}$, Ming K. Lim ${ }^{4}$ \\ ${ }^{1}$ Nottingham University Business School China, University of Nottingham Ningbo \\ China, Ningbo 315100, China \\ ${ }^{2}$ Business School, University of Strathclyde, 16 Richmond Street, Glasgow G1 1XQ, UK \\ ${ }^{3}$ Institute of Textiles and Clothing, Hong Kong Polytechnic University, \\ Hung Hom, Kowloon, Hong Kong \\ ${ }^{4}$ Derby Business School, University of Derby, Kedleston Road, Derby, DE22 1GB, UK
}

\begin{abstract}
Social media data contain rich information in posts or comments written by customers. If those data can be extracted and analysed properly, companies can fully utilise this rich source of information. They can then convert the data to useful information or knowledge, which can help to formulate their business strategy. This cannot only facilitate marketing research in view of customer behaviour, but can also aid other management disciplines. Operations management $(\mathrm{OM})$ research and practice with the objective to make decisions on product and process design is a fine example. Nevertheless, this line of thought is underresearched. In this connection, this paper explores the role of social media data in OM research. A structured approach is proposed, which involves the analysis of social media comments and a statistical cluster analysis to identify the interrelationships amongst important factors. A real-life example is employed to demonstrate the concept.
\end{abstract}

Keywords: Social media, Operations management, Content analysis, Cluster analysis 


\section{The role of social media data in operations and production management}

\section{Introduction}

Operations management (OM) has a long history (e.g. from the construction of ancient buildings thousand years ago, to military operations in the last couple of hundred of years), but modern OM research has its root in scientific management approach such as Taylorism (Mortenson, Doherty, and Robinson 2015) and its history since then is slightly longer than a century (Piercy 2012). Along this line of thought, traditional OM research is highly dominated by mathematical/ analytical-driven approaches, which later on, after the Second World War, evolved to operations research-based approaches (Fortun and Schweber 1993). Despite this highly mathematical-driven approaches in the last century there are many studies using different, non-mathematical, research approaches in OM discipline. Those studies incorporate other factors such as organisation behaviour in OM research studies. These studies include, but of course are not limited to, qualitative research techniques focusing on empirical data collection from interviews (Voss, Tsikriktsis, and Frohlich 2002), quantitative approaches such as using questionnaire survey to collect empirical data confirming new research models (Frohlich 2002), and so on. A more recent trend is the data-driven approach and hence, how to handle unstructured data are an emerging theme (Mortenson, Doherty, and Robinson 2015). Social media data are an example of such unstructured data.

Increasing popularity of Facebook, Twitter and other social media platforms has led to the availability of huge amount of valuable information. As a consequence, those social media platforms have generated a good source of data which are available openly to the public, and of course to researchers. In short, social media websites of companies are the platforms for customers to exchange their comments, probably with the organisations' interests (Xiang and Gretzel 2010). The information is particularly useful for analysing consumer behaviour (Mostafa 2013; Turri, Smith, and Kemp 2013), which can then help formulate business strategy (Ngai, Xiu, and Chau 2009). Nevertheless, how to make good use of the information is a challenge. Furthermore, application of the social media data for OM research has not been well attended. This can be verified by a simple simultaneous search of two keywords 'social media' and 'operations management' in Google Scholar. Having said that, social media is useful in many OM-related disciplines. This will be discussed in more detail in Section 2.

The aim of this paper is to explore a proper approach to analyse social media data for OM applications. The main objective is to help identify the factors/themes/issues from the social media data through content and cluster analysis. Applications could be linked to product development, process design and also supply chain management. This can then associate to and facilitate decision-making research, which is the main concern of OM research. The focus of this paper is put on product development with respect to different OM performance indicators in order to demonstrate the concept. This is facilitated by the latest version of NVivo, a content analysis tool, which incorporates a new web browser plug-in called NCapture capable of capturing social media data (in raw format). This plug- 
in provides a channel to download associated social media data for further analysis by the software NVivo.

The rest of this paper is organised as follows. Section 2 reviews the background of mining social media data and the associated studies in relation to operations management. It is found that this area is under studied. Section 3 reveals the research method of this paper, including how to access social media data, and the procedures to analyse the data. Section 4 then summarises the results from the content analysis and cluster analysis. It also presents the findings. Section 5 concludes this paper.

\section{Related studies on Utilising Social Media Data}

Social media has existed in various forms even before the introduction of the Internet, and hence are not new. However, currently the term 'social media' is mostly referred to the online applications that allow users exchanging their comments. Facebook and Twitter are typical examples of such social media platforms, although the latter may be specifically referred to as microblog (Kwak et al. 2010). This is linked to the development of Web 2.0 (Wirtz, Piehler, and Ullrich 2013), in which 'content and applications are no longer created and published by individuals, but instead are continuously modified by all users in a participatory and collaborative fashion' (Kaplan and Haenlein 2010). In this research, the term 'social media' is referred to such online applications. Usage of such applications has been soaring dramatically at an unbelievably explosive rate, which also means that quoting how many people who have registered with Facebook, for example, is quite meaningless as the number will become dated very quickly.

Definition of secondary data is textbook knowledge thus it is not reproduced here. Nevertheless, it is worth mentioning that secondary data are those data which normally 'have not been collected with a specific research purpose' (Sørensen, Sabroe, and Olsen 1996); as otherwise they should be classified as primary data. In addition, they are published data that already exist and are available to other researchers while answering their own research questions (Cowton 1998). Therefore, social media data, which are openly accessible and contain a large set of information for no specific research purpose, are considered to be secondary data. This assertion is also supported by researchers including Eltantawy and Wiest (2011). There are of course other types of secondary data and some of them are available in a more structured format. For example, in the economic field, data-sets containing economic-related data such as GDP, population, income distribution can be used for econometric analysis (Atkinson and Brandolini 2001). These data-sets are not limited to research purposes, and in fact many of them are originated from government agencies (Thomas and Heck 2001), and thus it is not surprising that they are used in relation to government policies. Company reports which contain financial data can also be considered as secondary data (Lodorfos and Boateng 2006). Readers are referred to Cowton (1998) for a more comprehensive review on different types of secondary data. Unfortunately, not all secondary data-sets are well structured, which is definitely a disadvantage (Sørensen, Sabroe, and Olsen 1996). Social media data is a typical example. Therefore, one of the objectives of this research is to extract useful information from such unstructured data-sets. 
With the above backdrop, social media data, which are openly available to the public and are free of charge, can be good source of information for both industrial practitioners and researchers. Not surprisingly those data have been already utilised in the marketing domain in the last few years. For example, social media data have changed the promotion mix in marketing communication (Mangold and Faulds 2009), simply because consumer-toconsumer communication is easier with the help of social media websites. Travellers are convenient to make use of social media websites to search for travelling information online, which reduces the reliance on travel agencies and hence, the impact of the associated marketing activities (Xiang and Gretzel 2010). This is equally applicable to other domains such as the health care sector (Thackeray et al. 2008), public relations (Eyrich, Padman and Sweetser 2008) Wang (2015) demonstrated that social media is one of the features that affect the positioning of smartphone via a case study. Despite the potential benefits of utilising social media data, companies still fail to extract the full capabilities of such websites (Culnan, McHugh, and Zubillaga 2010).

Like other data, usage of social media data is not free of criticisms. Marketers find it difficult to quantify the return of investment in social media websites; moreover the associated analysis is also difficult, if not impossible, to assess, especially if traditional approaches are employed (Hoffman and Fodor 2010). Another challenge is the subjectivity of the data. Social media websites are essentially the platforms to exchange word-of-mouth information electronically (Litvin, Goldsmith, and Pan 2008; Jansen et al. 2009; Shih, Lai, and Cheng 2013). This, on the one hand, can positively affect online consumption decision (Cheung, Lee, and Rabjohn 2008), but on the other hand, this may add additional uncertainty regarding the credibility and persuasiveness of the information being used (Cheung et al. 2009; Zhang, Craciun, and Shin 2010). Therefore, research extracting high quality information from social media data are very popular especially in the computer science domain (e.g. Agichtein et al. 2008; Gilbert and Karahalios 2009; Asur and Huberman 2010). The scholars of this strand of research aim to develop intelligent data mining approaches in so doing. For example, Asur and Huberman (2010) developed an approach to better forecast future events based on Twitter data. These algorithms are of significant academic value, but may not be user-friendly enough in real-life applications due to their complexity.

Although, social media data are not linked to OM attributes directly, such enormous size of data-set still provides useful information for research purpose and has some practical applications. Unfortunately, there are not many studies available in the literature. Amongst them, Noone, McGuire and Rohlfs (2011) suggested that such data would be useful in hotel revenue management, in spite of the fact that no systematic approach was proposed. Yates and Paquette (2011) discussed how social media can facilitate knowledge sharing during a disastrous event. Their discussions; however, is limited to high level implications mainly on managing the data across boundaries and the challenges of using social media data. More recently, Hu et al. (2013) made use of social media data to assess the risk associated with software projects. A comprehensive approach is proposed. 
In this connection, this research aims to address three gaps identified above. First, the application of this research is on a typical OM issue, namely, product development based on the high level OM measurements from social media websites. Second, the proposed qualitative content and statistical cluster analysis are employed to reveal the factors and their interrelationship from the social media data. This can help quantifying the qualitative data for further applications. Finally, the proposed approach can also help alleviate the subjectivity of the social media data through the statistical analysis. This is because the approach looks into high level aggregate data, rather than individual customers' comments separately. Of course, this cannot completely remove such subjectivity, but can definitely help to reduce the associated negative impact. The proposed approach is practical yet statistically robust enough for real-life applications. Details are presented in Section 3.

\section{Research Method}

For the purpose of this research data from Facebook, one of the most popular social media platforms, was used in order to demonstrate the procedures for utilisation of social media data in OM research. To retain focus on product development as the subject of this research, it was decided to employ Samsung's mobile Facebook page in relation to the launch of the Samsung smartphone, Samsung Galaxy S4 in late April 2013. That was the latest model when the research was conducted. As it was mentioned in the introduction to this paper, the data were collected with the help of NCapture, a plug-in for NVivo 10. Four months of data (10 June-10 September 2013) in the form of consumers' comments were downloaded for analysis. The content analysis was carried out using conceptual analysis and then relational analysis with the help of statistical cluster analysis, as visualised in the flow diagram below (Figure 1). A detailed discussion of data collection process and procedure for data analysis is provided next.

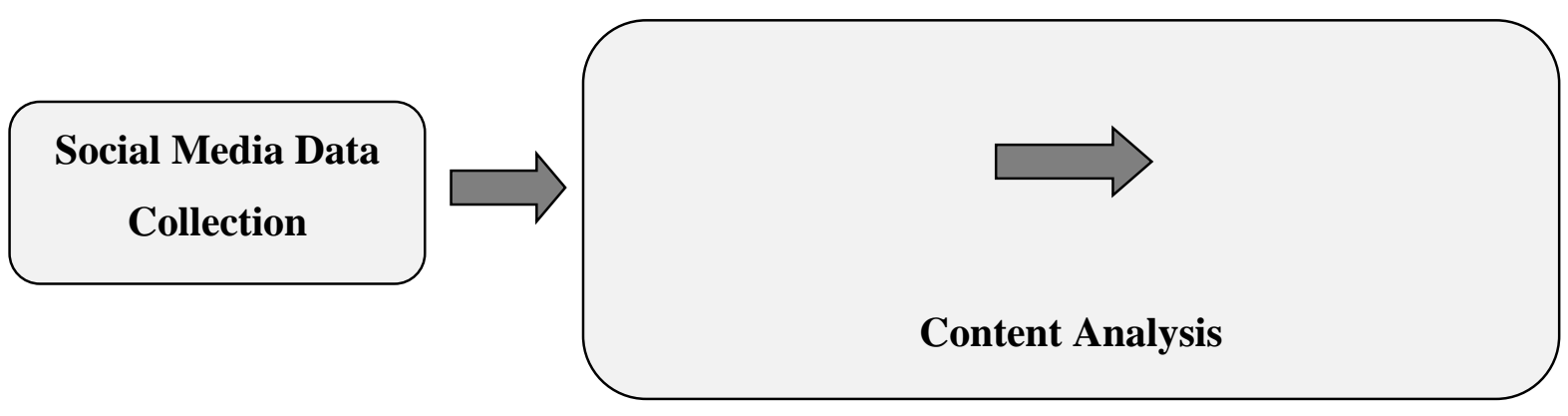

Figure 1. Research method

Many research studies associated with social media research linked to the social media metrics, not the data themselves. For example, Ralston et al. (2014) made use of such metrics of tweeters (e.g. number of messages per day, number of followers, etc.) to analyse the use of social media by surgical colleges. Rui, Liu, and Whinston (2013) tried to classify tweets by dividing tweets into intention tweets and sentiment tweets. In those students; however, the 'content' of the social media data have not been explored. Perhaps the first attempt to explore the value of social media content was made by Denecke and Nejdl (2009). The researchers aimed to evaluate how valuable medical social media data is. To reach this objective they carried out content analysis of health-related information provided 
on social media sites (e.g. blogs and Wikis). Based on the analysis Denecke and Nejdl (2009) distinguish between informative and affective comments and classified social media sites in accordance to content posted. The present study aims to make a step further. Specifically in this study content, analysis is employed to convert social media data into quantifiable factors and then retrieve the relationship between those factors. Following the proposed approach it would be possible to make use of social media data for further applications (e.g. new product development) and thus reveal a true value of social media data

\subsection{Data collection}

Data for this study was accessed from the Samsung mobile Facebook page.1 It consisted of recently posted comments by Facebook users on Samsung mobile Facebook page, selected and captured as a data-set using NCapture for NVivo 10. This data includes consumers' comments from 10 June to 10 September 2013. Overall 128,371 comments were downloaded. The researchers then searched for comments including '4'. Finally, posts were skimmed for comments related to Samsung Galaxy S4. Only comments posted in English language were considered for analysis, comments posted in any other language but English were ignored.

\subsection{Content analysis}

For the purpose of this research two general categories of content analysis were employed: conceptual analysis and relational analysis. The conceptual analysis was used to establish the existence and frequency of concepts/codes in the data. The relational analysis building on conceptual analysis aided examination of the relationships amongst concepts/codes in the data. The approach of conducting conceptual analysis and relational analysis is discussed in Section 3.2.1.

\subsubsection{Conceptual analysis}

The conceptual analysis involves quantifying the occurrence in the data-set of concept/codes chosen for examination, which can be both implicit and explicit in nature. As data used for the purpose of this research comes from a social media website where users freely post their comments, the data gathered seems to be implicit and hence it is subject to limitations previously discussed in Section 2.

In order to overcome possible limitations of using implicit secondary data, including possible subjectivity in the analysis and thus poor reliability and validity of research findings, the following coding strategy was employed. First the concepts/codes were clearly defined based on the objectives of operation performance indices. This study focuses on OM so the five operations performance indicators are adopted. Next, to each concept/code was allocated an individual item in order to reduce subjectivity while analysing the data. Finally, sample comments were provided to help the readers understand the definitions of the items. Table 1 presents concepts/codes, allocated items, the label attached to each item, as well as the sample comments. 
Having clearly defined concepts/codes, the coding process was carried out. The coding was based on selective reduction of comments into meaningful units which then were coded according to previously defined concepts/codes. Overall 1800 items were selected for final analysis (see Table 2). This step is essential text mining process, which 'attempts to identify patterns in the text and predict outcomes' (Buddhakulsomsiri et al. 2006).

\begin{tabular}{|c|c|c|c|}
\hline Concept/ Code & Item & Label & Comment \\
\hline Speed & $\begin{array}{l}\text { Delivering the product } \\
\text { to the consumer as soon } \\
\text { as possible }\end{array}$ & S1 & $\begin{array}{l}\text { Questions regarding product } \\
\text { introduction date }\end{array}$ \\
\hline \multirow[t]{4}{*}{ Dependability } & $\begin{array}{l}\text { Doing things on time as } \\
\text { promised }\end{array}$ & D1 & $\begin{array}{l}\text { Questions regarding the } \\
\text { delivery update of update }\end{array}$ \\
\hline & $\begin{array}{l}\text { Developing } \\
\text { trustworthiness }\end{array}$ & D2 & $\begin{array}{l}\text { Comments regarding } \\
\text { consumers' willingness/ } \\
\text { unwillingness to purchase the } \\
\text { product }\end{array}$ \\
\hline & $\begin{array}{l}\text { Using effective } \\
\text { equipment }\end{array}$ & D3 & - \\
\hline & $\begin{array}{l}\text { Developing effective } \\
\text { communication }\end{array}$ & D4 & $\begin{array}{l}\text { All kinds of questions asked } \\
\text { by consumers and help } \\
\text { requests }\end{array}$ \\
\hline \multirow[t]{2}{*}{ Flexibility } & $\begin{array}{l}\text { Being able to change } \\
\text { operations to fulfil new } \\
\text { requirements }\end{array}$ & $\mathrm{F} 1$ & $\begin{array}{l}\text { Comments suggesting } \\
\text { introduction of the product } \\
\text { and its features }\end{array}$ \\
\hline & $\begin{array}{l}\text { Being able to introduce } \\
\text { new products or modify } \\
\text { existing products }\end{array}$ & $\mathrm{F} 2$ & $\begin{array}{l}\text { Comments suggesting } \\
\text { improvement of the product } \\
\text { and its features }\end{array}$ \\
\hline \multirow[t]{4}{*}{ Quality } & Meeting expectations & Q1 & $\begin{array}{l}\text { Consumers' statements } \\
\text { outlining their satisfaction/ } \\
\text { dissatisfaction with the } \\
\text { product related to consumers' } \\
\text { expectations }\end{array}$ \\
\hline & Fulfilling requirements & Q2 & $\begin{array}{l}\text { Comments regarding } \\
\text { product's features and } \\
\text { problems encountered due to } \\
\text { faulty features }\end{array}$ \\
\hline & $\begin{array}{l}\text { Maintaining effective } \\
\text { communication }\end{array}$ & Q3 & - \\
\hline & Doing things right & Q4 & $\begin{array}{l}\text { Comments concerning } \\
\text { satisfaction/ dissatisfaction } \\
\text { (e.g. I like S4) }\end{array}$ \\
\hline Cost & $\begin{array}{l}\text { Doing things } \\
\text { economically at low } \\
\text { price }\end{array}$ & $\mathrm{C} 1$ & $\begin{array}{l}\text { Questions regarding product } \\
\text { price and cost of product } \\
\text { repair }\end{array}$ \\
\hline
\end{tabular}




\begin{tabular}{|l|l|l|l|}
\hline Lead time & Production time & L1 & $\begin{array}{l}\text { Questions regarding product } \\
\text { update }\end{array}$ \\
\hline
\end{tabular}

Table 1. Definition of concepts/ codes

\begin{tabular}{|l|c|c|}
\hline Concept/ Code- Item & Label & $\begin{array}{c}\text { No of } \\
\text { References }\end{array}$ \\
\hline $\begin{array}{l}\text { Speed- Delivering the product to the consumer as soon as } \\
\text { possible }\end{array}$ & S1 & 93 \\
\hline Dependability- Doing things on time as promised & D1 & 25 \\
\hline Dependability- Developing trustworthiness & D2 & 148 \\
\hline Dependability- Using effective equipment & D3 & 0 \\
\hline Dependability- Developing effective communication & D4 & 456 \\
\hline $\begin{array}{l}\text { Flexibility- Being able to change operations to fulfil new } \\
\text { requirements }\end{array}$ & F1 & 13 \\
\hline $\begin{array}{l}\text { Flexibility- Being able to introduce new products or modify } \\
\text { existing products }\end{array}$ & F2 & 106 \\
\hline Quality- Meeting expectations & Q1 & 139 \\
\hline Quality- Fulfilling requirements & Q2 & 366 \\
\hline Quality- Maintaining effective communication & Q3 & 0 \\
\hline Quality- Doing things right & Q4 & 287 \\
\hline Cost- Doing things economically at low price & C1 & 127 \\
\hline Lead time- Production time & L1 & 40 \\
\hline
\end{tabular}

Table 2. Number of clusters

\subsubsection{Relational analysis}

As mentioned before building on conceptual analysis, the relational analysis was conducted to examine relationships amongst concepts/codes. In order to statistically examine these relationships, the cluster analysis was conducted and Pearson correlation coefficient test was run. The results of cluster analysis and Pearson correlation coefficient test are discussed next.

Pearson correlation coefficient is a typical Euclidean distance-based measurement for similarity test. Apart from this index, there are other alternative tests that can be employed to measure relationship between concepts/codes. For example, cosine-based similarity (Silva et al. 2013; Xia, Zhang, and Li 2015) or adjusted cosine similarity (BarragánsMartínez et al. 2010; Birtolo and Ronca 2013), to list a few. Pearson correlation coefficient is adopted in this study because it is a built-in function in NVivo 10, software used for cluster analysis. The test is sufficient for demonstration purpose, but future research is encouraged to compare the results obtained from different similarity measures.

\section{Results and Discussions}

Content analysis alone can help researchers to understand the qualitative content from a data-set (i.e. Facebook comments in this paper). Nevertheless, while the size of today's 
social media data are simply too big to be handled the management still requires the strategic understanding of the analysis. Therefore, cluster analysis is in its nature a statistical classification tool that can help researchers to classify a large data-set into a number of subsets, which are sometimes referred to as objects (Ketchen and Shook 1996). It is very useful, for instance, for marketing research to analyse a data-set without prior assumptions of the relationships of the factors of concern (Punj and Stewart 1983). Equally important is the reduction process of the number of factors of our concern (Hair et al. 2010). This is analogous to factor analysis. Above-mentioned benefits will be showcased in this section.

Following the procedures outlined in Section 3, clusters of important OM criteria (as shown in Table 2) in relation to the consumers' comments on the chosen product can be formed. Figure 2 depicts the dendrogram of the analysis. Dendrogram is a tree-like graphical representation to display the results generated from cluster analysis (Hair et al. 2010). This is sometimes called 'classification tree'. In the dendrogram, similar items, factors or in this case concepts/codes are 'clustered' together in terms of the similarity against other factors, and vice versa so that different items are 'separated' by distance. In other words, highly correlated factors are grouped together as a hierarchy of clusters that can facilitate the later decision-making process. This is out of the scope of this paper, but will be addressed briefly later in this section.

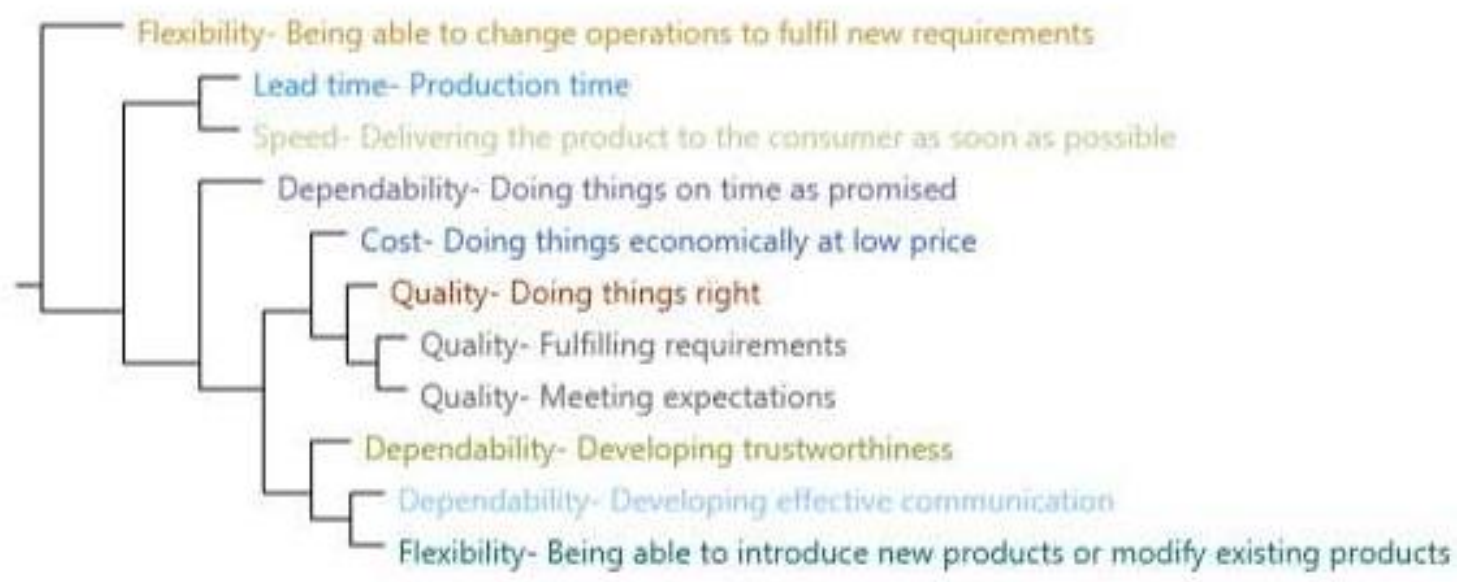

Figure 2. Dendrogram of the cluster analysis

Before discussing the implications of Figure 2, the query how the clusters can be formed will be addressed. As a matter of fact, there are many algorithms but the one adopted in this research is the use of Pearson correlation coefficient, which is a commonly employed statistical test for this purpose (e.g. Ahlgren, Jarneving, and Rousseau 2003; Cheung and Li 2012; Zhang et al. 2013; Bouguettaya et al. 2015). Table 3 lists the coefficients and the corresponding pair of items (i.e. labels in the table). The closer the coefficient is to $1(-1)$, the higher is the similarity (dissimilarity) of the pair. A value of zero means the pair is not correlated to each other (i.e. they have no linear relationship at all). For example, Q4 and F1 pair has a value of 0.670879 and it is five levels apart in Figure 2. Q1 and F1 pair is even worse and has a value of 0.629375. This pair is six levels apart in Figure 2. 


\begin{tabular}{|c|c|c|c|c|c|}
\hline Label & Label & $\begin{array}{c}\text { Pearson } \\
\text { correlation } \\
\text { coefficient }\end{array}$ & Label & Label & $\begin{array}{c}\text { Pearson } \\
\text { correlation } \\
\text { coefficient }\end{array}$ \\
\hline Q2 & Q1 & 0.971369 & S1 & Q4 & 0.767503 \\
\hline Q4 & Q2 & 0.970377 & D4 & D1 & 0.755551 \\
\hline Q4 & Q1 & 0.968907 & S1 & C1 & 0.751035 \\
\hline Q2 & D4 & 0.948166 & S1 & Q2 & 0.733648 \\
\hline F2 & D4 & 0.939958 & Q4 & D1 & 0.732828 \\
\hline Q4 & C1 & 0.937702 & F2 & F1 & 0.722472 \\
\hline D4 & D2 & 0.935226 & Q2 & D1 & 0.722408 \\
\hline Q4 & D4 & 0.933664 & D1 & C1 & 0.721811 \\
\hline Q2 & C1 & 0.928996 & F2 & D1 & 0.719562 \\
\hline Q1 & C1 & 0.923178 & D2 & D1 & 0.718563 \\
\hline Q4 & F2 & 0.905635 & F1 & D4 & 0.712495 \\
\hline D4 & C1 & 0.901911 & Q1 & D1 & 0.709018 \\
\hline Q4 & D2 & 0.899569 & Q4 & L1 & 0.707582 \\
\hline F2 & D2 & 0.896237 & S1 & D1 & 0.698561 \\
\hline Q2 & F2 & 0.895921 & F1 & D2 & 0.682489 \\
\hline S1 & L1 & 0.894889 & Q2 & L1 & 0.682228 \\
\hline Q1 & D4 & 0.887127 & S1 & Q1 & 0.670933 \\
\hline Q2 & D2 & 0.872725 & Q4 & F1 & 0.670879 \\
\hline D2 & C1 & 0.872062 & L1 & C1 & 0.66919 \\
\hline S1 & D4 & 0.857865 & Q2 & F1 & 0.665662 \\
\hline F2 & C1 & 0.854281 & F1 & C1 & 0.662722 \\
\hline S1 & F2 & 0.853988 & S1 & F1 & 0.644967 \\
\hline S1 & D2 & 0.853459 & Q1 & F1 & 0.629375 \\
\hline Q1 & F2 & 0.840803 & L1 & D1 & 0.621831 \\
\hline Q1 & D2 & 0.834816 & Q1 & L1 & 0.614663 \\
\hline L1 & F2 & 0.829576 & F1 & D1 & 0.577654 \\
\hline L1 & D4 & 0.803419 & L1 & F1 & 0.570809 \\
\hline L1 & D2 & 0.800131 & & & \\
\hline & Ta 3. & & & \\
\hline
\end{tabular}

Table 3. Pearson Correlation Coefficient of the items

The most straightforward benefit of the analysis is that researchers can formulate or verify (potential) hypotheses based on the similarities, and hence also dissimilarities, amongst the criteria. Taking Figure 2 as an example, it is not surprising that production lead time (L1) is highly related to another measure, namely, speed to deliver the product to the consumer as soon as possible (S1). Their Pearson correlation coefficient is 0.894889 , which is very high. The results from the cluster analysis confirm this assertion as L1 and S1 are grouped as one cluster and hence a positive relationship between these two factors can be hypothesised for further analysis such as in a quantitative questionnaire survey. In contrast, Figure 2 tells a potentially new relationship between an item under dependability (developing effective communication, D4) and flexibility (being able to introduce new products or modify existing products, F2). The corresponding Pearson correlation 
coefficient is 0.939958 , which is even higher than the L1-S1 pair. This finding is worth investigating and may lead to a new theoretical development and contributions, hopefully.

Some interesting findings can also be extracted at a higher level. For example, one may wonder if the six dimensions are homogenous measures. From Figure 2 and Table 3, it is safe to conclude that the items under the dimensions can correlate to the items under other dimensions. Quality is one of such dimensions. Above examples demonstrate how the cluster analysis provides preliminary evidence to help researchers identify potential hypotheses (i.e. relationships amongst the factors). Figure 3 is another way to present the dendrogram that can show the nested nature of the clusters as discussed here. The next step is highly dependent on the application domain.

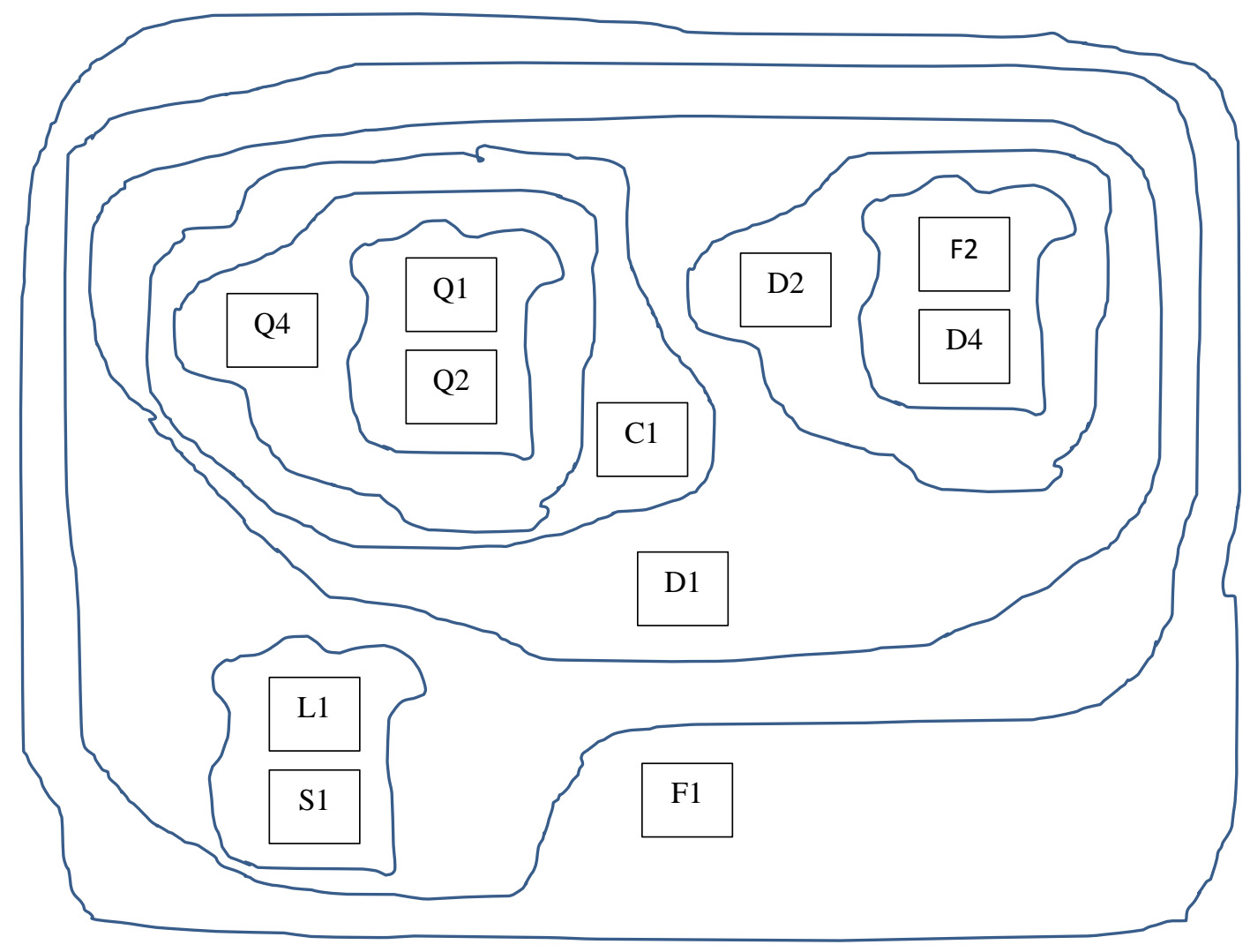

Figure 3. Nested cluster diagram

One direct application of the result from this cluster analysis is to help develop decisionmaking models for operations managers. In this research, the factors are related to new product development. One commonly used framework is the analytic hierarchy process (AHP), which was developed by Saaty (1990). AHP help decision-makers to identify the best alternatives following a hierarchical model, which consists of a number of criteria and sub-criteria for comparisons (Chan and Wang 2013). Taking the mobile phone design in this research as an example, the most direct approach to construct the hierarchy is to put the dimensions at a higher level followed by the items. This is illustrated in Figure 4. 


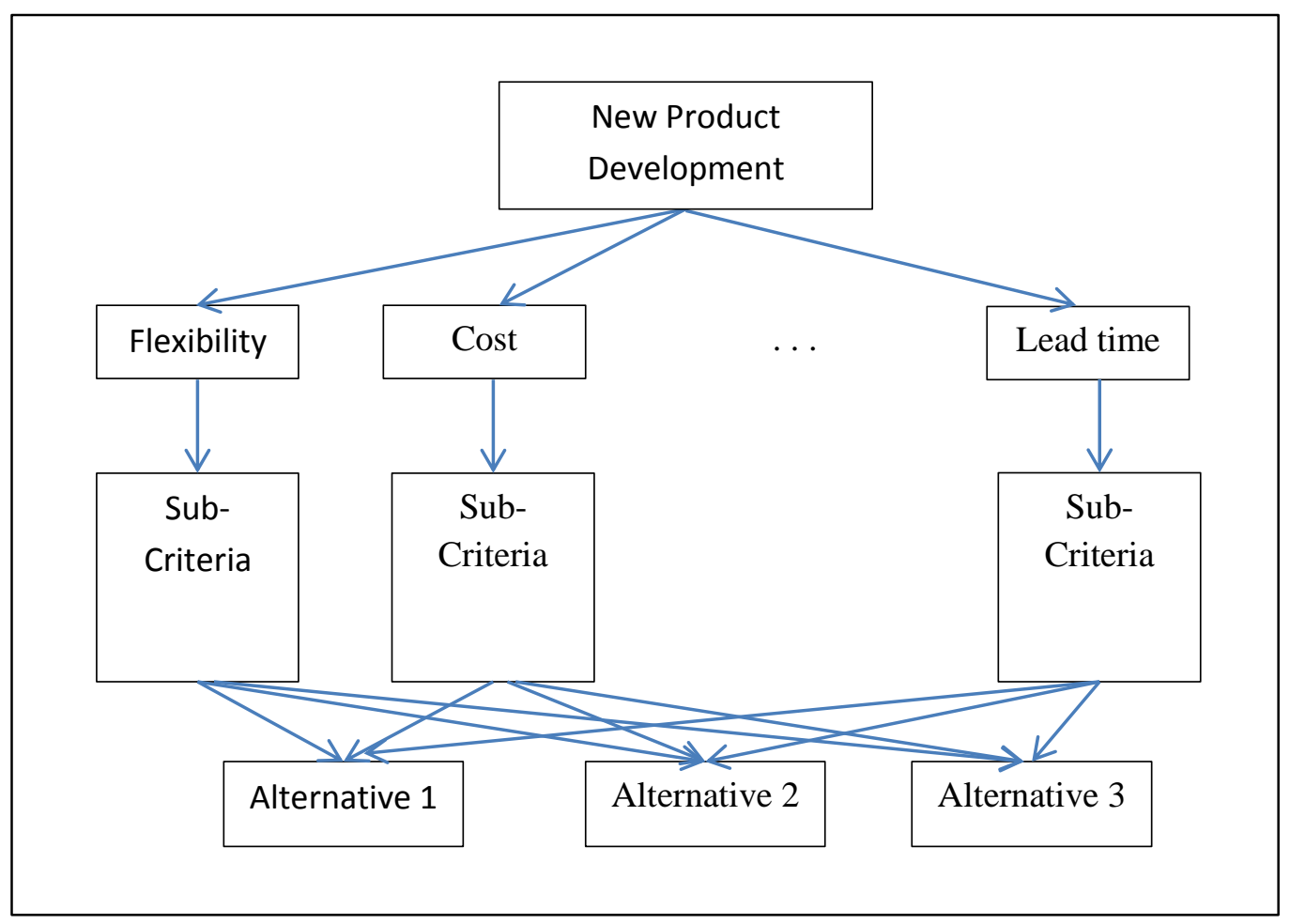

Figure 4. A typical hierarchy for AHP

This construction; however, is often criticised because of the theoretical development of the model. In other words, many researchers would consider the criteria and sub-criteria in Figure 4 as criteria defined arbitrarily. Thus, while comparing Figures 3 and 2, the implication of this research is self-explanatory. For example, Q1, Q2, Q4 and D1 can form one group to replace the quality dimension, D2, D4 and F2 can form another group to replace the Dependability dimension, etc. Hence, a different model can be constructed based on the social media data which are originated from end customers. In addition, the relative importance of conducting the pairwise comparison can be adjusted by the social media statistics. Referring to Table 2, the frequency of occurrence of Q1 and Q2 is 139 and 366, respectively. Obviously Q2 is considered more important than Q1 from consumers' point of view and the rating can be evaluated using a normalised scale. This helps to address another weakness of the AHP, which relies on expert judgement in the pairwise comparison. This is already a direct extension of this research.

Although this paper makes use of Facebook comments to demonstrate the proposed method, the method itself is not restricted to this type of social media data only. There is literally no limitation on the input data while using the proposed method and hence data from different types of social media platform can be fed into this approach for the analysis. Of course, some types of data may need preprocessing such as formatting or screening due to the diversified nature of social media data. In the future, OM research can collect data from this new channel together with the traditional channels (for example, expert judgement, interviews with production people and so on). The main and possible eventual objective of any business is to satisfy customers, and such social media data will be helpful to incorporate customers' voice into business strategy. Furthermore, social media data, in 
contrast to other types of secondary data, can be available readily from the Internet. This convenience could be an additional advantage to $\mathrm{OM}$ research. This research also demonstrates how social media data can be included in traditional main stream empirical research.

\section{Conclusions}

This research demonstrates a practical approach to utilise social media data and the focus is put on the OM perspective. The proposed procedures help quantify the qualitative social media data into clusters with similar characteristics for later applications. This is supported by a real-life example, namely, comments related to the model S4 posted on the Samsung mobile Facebook website. The research is multidisciplinary in nature and defines a multimethodological approach to blend social media research and OM research. Although, the main focus of this paper is put on factors related to product development, this research may be evolved to other areas.

The main contribution of this paper is to outline the approach to extract social media for later analysis. As mentioned above, this involves the quantification of social media data. This outcome can then be utilised in many applications, to name a few, empirical questionnaire survey, design of decision-making systems and so on. Nevertheless, the authors take a snapshot view on the data (to be precise, four months of data) for the purpose of this research project. This is a limitation of this research since the social media websites are kept updating and the corresponding data-set keeps growing. To address this, a realtime data crawling decision-support system coupled with the corresponding decisionmaking tools is required in order to monitor the dynamic comments on a real-time basis.

Another future direction of this research is to blend cluster analysis in this research with fuzzy theory to build decision-making models. Timm et al. (2004) suggested that clusters in the cluster analysis should be formed in a fuzzy manner; otherwise the data must be assigned exactly to one group (i.e. a yes or no question), which sometimes is not realistic. The subjectivity of consumers' comments adds an extra impreciseness onto the results. This research makes use of the statistical tool to analyse the similarities of the factors, which are drawn from the comments in order to reduce the impact of such subjectivity. Finally, fuzzy theory is a straightforward extension to this research. Fuzzy AHP (Chan et al. 2013) is one example how idea discussed in Section 4 can be developed further. This also helps to address any possible limitations of using social media data, such as its subjectivity.

\section{Reference}

Agichtein, E., Castillo, C., Donato, D., Gionis, A., and Mishne, G. (2008). Finding highquality content in social media. In Proceedings of the International Conference on Web Search and Web Data Mining, pp. 183-194. 
Ahlgren, P., Jarneving, B., and Rousseau, R. (2003). Requirements for a cocitation similarity measure, with special reference to Pearson's correlation coefficient. Journal of the American Society for Information Science and Technology, 54(6), 550-560.

Atkinson, A. B., and Brandolini, A. (2001). Promise and pitfalls in the use of" secondary" data-sets: Income inequality in OECD countries as a case study. Journal of Economic Literature, 39(3), 771-799.

Asur, S., and Huberman, B. A. (2010). Predicting the future with social media. In Proceedings of the IEEE/WIC/ACM International Conference on Web Intelligence and Intelligent Agent Technology (WI-IAT), Vol. 1, pp. 492-499.

Barragáns-Martínez, A. B., Costa-Montenegro, E., Burguillo, J. C., Rey-López, M., MikicFonte, F. A., and Peleteiro, A. (2010). A hybrid content-based and item-based collaborative filtering approach to recommend TV programs enhanced with singular value decomposition. Information Sciences, 180(22), 4290-4311.

Birtolo, C., and Ronca, D. (2013). Advances in Clustering Collaborative Filtering by means of Fuzzy C-means and trust. Expert Systems with Applications, 40(17), 6997-7009.

Bouguettaya, A., Yu, Q., Liu, X., Zhou, X., and Song, A. (2015). Efficient agglomerative hierarchical clustering. Expert Systems with Applications, 42(5), 2785-2797.

Buddhakulsomsiria, J., Siradeghyana, Y., Zakarian, A., and Li, X. (2006). Association rulegeneration algorithm for mining automotive warranty data. International Journal of Production Research, 44(14), 2749-2770.

Chan, H. K., and Wang, X. (2013). Fuzzy Hierarchical Model for Risk Assessment: Principles, Concepts, and Practical Applications. London: Springer.

Chan, H. K., Wang, X., White, G., and Yip, N. (2013). An Extended Fuzzy AHP approach for the evaluation of green product designs. IEEE Transactions on Engineering Management, 60(2), 327-339.

Cheung, C. F., and Li, F. L. (2012). A quantitative correlation coefficient mining method for business intelligence in small and medium enterprises of trading business. Expert Systems with Applications, 39(7), 6279-6291.

Cheung, C. M., Lee, M. K., and Rabjohn, N. (2008). The impact of electronic word-ofmouth: The adoption of online opinions in online customer communities. Internet Research, 18(3), 229-247.

Cheung, M. Y., Luo, C., Sia, C. L., and Chen, H. (2009). Credibility of electronic wordof-mouth: Informational and normative determinants of on-line consumer recommendations. International Journal of Electronic Commerce, 13(4), 9-38.

Cowton, C. J. (1998). The use of secondary data in business ethics research. Journal of Business Ethics, 17(4), 423-434.

Culnan, M. J., McHugh, P. J., and Zubillaga, J. I. (2010). How large US companies can use Twitter and other social media to gain business value. MIS Quarterly Executive, 9(4), 243-259.

Denecke K., and Nejdl W., (2009). How valuable is medical socoal media data? Content analysis of the medical web. Information Science 179, 1870- 1880

Eltantawy, N., and Wiest, J. B. (2011). Social media in the Egyptian revolution: Reconsidering resource mobilization theory. International Journal of Communication, 5, 1207-1224.

Eyrich, N., Padman, M. L., and Sweetser, K. D. (2008). PR practitioners' use of social media tools and communication technology. Public Relations Review, 34(4), 412-414. 
Fortun, M., \& Schweber, S. S. (1993). Scientists and the legacy of World War II: The case of operations research (OR). Social Studies of Science, 23(4), 595-642.

Frohlich, M. T. (2002). Techniques for improving response rates in OM survey research. Journal of Operations Management, 20(1), 53-62.

Gilbert, E., and Karahalios, K. (2009). Predicting tie strength with social media. In Proceedings of the SIGCHI Conference on Human Factors in Computing Systems, pp. 211-220.

Hair, J. F., Black, W. C., Bahin, B. J., and Anderson, R. E. (2010). Multivariate data analysis: A global perspective. London: Pearson Education.

Hoffman, D. L., and Fodor, M. (2010). Can you measure the ROI of your social media marketing. MIT Sloan Management Review, 52(1), 41-49.

Hu, Y., Du, J., Zhang, X., Hao, X., Ngai, E. W. T., Fan, M., and Liu, M. (2013). An integrative framework for intelligent software project risk planning. Decision Support Systems, 55(4), 927-937.

Jansen, B. J., Zhang, M., Sobel, K., and Chowdury, A. (2009). Twitter power: Tweets as electronic word of mouth. Journal of the American Society for Information Science and Technology, 60(11), 2169-2188.

Kaplan, A. M., and Haenlein, M. (2010). Users of the world, unite! The challenges and opportunities of social media. Business Horizons, 53(1), 59-68.

Ketchen, D. J., and Shook, C. L. (1996). The application of cluster analysis in strategic management research: an analysis and critique. Strategic Management Journal, 17(6), 441-458.

Kwak, H., Lee, C., Park, H., and Moon, S. (2010). What is Twitter, a social network or a news media? In Proceedings of the 19th International Conference on World Wide Web, pp. 591-600.

Litvin, S. W., Goldsmith, R. E., and Pan, B. (2008). Electronic word-of-mouth in hospitality and tourism management. Tourism Management, 29(3), 458-468.

Lodorfos, G., \& Boateng, A. (2006). The role of culture in the merger and acquisition process: Evidence from the European chemical industry. Management Decision, 44(10), 1405-1421.

Mangold, W. G., and Faulds, D. J. (2009). Social media: The new hybrid element of the promotion mix. Business Horizons, 52(4), 357-365.

Mortenson, M. J., Doherty, N. F., and Robinson, S. (2015). Operational research from Taylorism to Terabytes: A research agenda for the analytics age. European Journal of Operational Research, 241(3), 583-595.

Mostafa, M. M. (2013). More than words: Social networks' text mining for consumer brand sentiments. Expert Systems with Applications, 40(10), 4241-4251.

Noone, B. M., McGuire, K. A., and Rohlfs, K. V. (2011). Social media meets hotel revenue management: Opportunities, issues and unanswered questions. Journal of Revenue and Pricing Management, 10(4), 293-305.

Ngai, E.W.T., Xiu, L., and Chau, D.C.K. (2009). Application of data mining techniques in customer relationship management: A literature review and classification. Expert Systems with Applications, 36(2), 2592-2602.

Piercy, N. (2012). Business history and operations management. Business History, 54(2), 154-178. 
Punj, G., and Stewart, D. W. (1983). Cluster analysis in marketing research: review and suggestions for application. Journal of Marketing Research, 20(2), 134-148.

Ralston, M. R., O'Neill, S. Wigmore, S. J., and Harrison, E. M. (2014). An exploration of the use of social media by surgical colleges. International Journal of Surgery, 12(12), 1420-1427.

Rui, H., Liu, Y., and Whinston, A. (2013). Whose and what chatter matters? The effect of tweets on movie sales. Decision Support Systems, 55(4), 863-870.

Saaty, T. L. (1990). How to make a decision: the analytic hierarchy process. European Journal of Operational Research, 48(1), 9-26.

Shih, H. -P., Lai, K. -H., and Cheng, T. C. E. (2013). Informational and Relational Influences on Electronic Word of Mouth: An Empirical Study of an Online Consumer Discussion Forum. International Journal of Electronic Commerce, 17(4), 137-166.

Silva, T., Guo, Z., Ma, J., Jiang, H., and Chen, H. (2013). A social network-empowered research analytics framework for project selection. Decision Support Systems, 55(4), 957-968.

Sørensen, H. T., Sabroe, S., and Olsen, J. (1996). A framework for evaluation of secondary data sources for epidemiological research. International Journal of Epidemiology, 25(2), 435-442.

Thackeray, R., Neiger, B. L., Hanson, C. L., and McKenzie, J. F. (2008). Enhancing promotional strategies within social marketing programs: use of Web 2.0 social media. Health Promotion Practice, 9(4), 338-343.

Thomas, S. L., and Heck, R. H. (2001). Analysis of large-scale secondary data in higher education research: Potential perils associated with complex sampling designs. Research in higher education, 42(5), 517-540.

Timm, H., Borgelt, C., Döring, C., and Kruse, R. (2004). An extension to possibilistic fuzzy cluster analysis. Fuzzy Sets and Systems, 147(1), 3-16.

Turri, A. M., Smith, K. H., \& Kemp, E. (2013). Developing affective brand commitment through social media. Journal of Electronic Commerce Research, 14(3), 201-214.

Voss, C., Tsikriktsis, N., \& Frohlich, M. (2002). Case research in operations management. International Journal of Operations \& Production Management, 22(2), 195-219.

Wang, C.-H. (2015). A market-oriented approach to accomplish product positioning and product recommendation for smart phones and wearable devices. International Journal of Production Research, 53(8), 2542-2553.

Wirtz, B. W., Piehler, R., and Ullrich, S. (2013). Determinants of social media website attractiveness. Journal of Electronic Commerce Research, 14(1), 11-33.

Xia, P., Zhang, L., and Li, F. (2015). Learning similarity with cosine similarity ensemble. Information Sciences, 307, 39-52.

Xiang, Z., and Gretzel, U. (2010). Role of social media in online travel information search. Tourism Management, 31(2), 179-188.

Yates, D., and Paquette, S. (2011). Emergency knowledge management and social media technologies: A case study of the 2010 Haitian earthquake. International Journal of Information Management, 31(1), 6-13.

Zhang, J. Q., Craciun, G., and Shin, D. (2010). When does electronic word-of-mouth matter? A study of consumer product reviews. Journal of Business Research, 63(12), 13361341. 
Zhang, W. Y., S. Zhang, S., Chen, Y. G., and Pan, X. W. (2013). Combining social network and collaborative filtering for personalised manufacturing service recommendation. International Journal of Production Research, 51(22), 6702-6719. 